\begin{tabular}{|c|l|}
\hline Title & Influence of the Gulf Stream on the troposphere \\
\hline Author(s) & Minobe, Shoshiro; Kuwano-Y oshida, A kira; Komori, Nobumasa; Xie, Shang-Ping; Small, Richard Justin \\
\hline Citation & $\begin{array}{l}\text { Nature, 452(7184), 206-209 } \\
\text { https://doi.org/10.1038/hature06690 }\end{array}$ \\
\hline Issue Date & 2008-03_13 \\
\hline Doc URL & http://hdl.handle.net/2115/39215 \\
\hline Type & article(author version) \\
\hline File Information & Minobe_etal_GS2A tmos.pdf \\
\hline
\end{tabular}

Instructions for use 


\title{
Influence of the Gulf Stream on the troposphere
}

\author{
Shoshiro Minobe ${ }^{1}$, Akira Kuwano-Yoshida ${ }^{2}$, Nobumasa Komori ${ }^{2}$, Shang-Ping Xie ${ }^{3,4}$, \\ and Richard Justin Small ${ }^{3}$
}

${ }^{1}$ Department of Natural History Sciences, Graduate School of Science, Hokkaido University, Sapporo, Japan.

${ }^{2}$ Earth Simulator Center, Japan Agency for Marine-Earth Science and Technology, Yokohama, Japan.

${ }^{3}$ International Pacific Research Center, University of Hawaii at Manoa, Honolulu, Hawaii, U. S. A.

${ }^{4}$ Department of Meteorology, University of Hawaii at Manoa, Honolulu, Hawaii, U. S. A.

The Gulf Stream transports large amounts of heat from the tropics to mid- and high-latitudes, and thereby affects cyclogenesis ${ }^{1,2}$ and low cloud formation ${ }^{3}$. Its influence on climate on monthly and longer timescales remains poorly understood, however. In particular, it is unclear to what depth the warm current affects the free atmosphere above the marine atmospheric boundary layer. Here we consider the Gulf Stream's influence on the troposphere using a combination of operational weather analyses, satellite observations, and an atmospheric general circulation model $^{4}$. Our results reveal that the Gulf Stream affects the entire troposphere. In the marine boundary layer, atmospheric pressure adjustments to sharp sea surface temperature gradients lead to surface wind convergence that anchors a narrow precipitation band along the Gulf Stream. In this rain band, upward motions and cloud formation extend into the upper troposphere as corroborated by the frequent occurrence of very cold cloud-top temperatures. These mechanisms offer a direct pathway by which the Gulf Stream can affect the atmosphere both locally and possibly in remote regions via planetary wave propagation ${ }^{5,6}$. This pathway may have implications for our understanding of climate change because the Gulf Stream is the upper limb of the Atlantic meridional overturning circulation, which displays large variations in records of past climate change ${ }^{7}$ and is predicted to slow down in response to global warming ${ }^{8}$.

It is a challenging task to isolate the climatic influence of the Gulf Stream from energetic weather variability using conventional observations which are spatially and temporally sporadic. Recently, high-resolution satellite observations of surface winds make it possible to map the influence of the Gulf Stream ${ }^{9,10}$ and other major Sea Surface Temperature (SST) fronts ${ }^{11-14}$ on the near-surface atmosphere. The Gulf Stream affects the $10 \mathrm{~m}$ wind climatology as observed by the QuikSCAT satellite ${ }^{15}$, with wind divergence and convergence on the cold and warm flanks of the Gulf Stream front, respectively $^{9,10}$ (Fig. 1a). However, the mechanism for the SST fronts to influence surface winds is still under much debate ${ }^{9,10}$ 
The identification of the responsible mechanism has been hampered by the need to know parameters not available from satellite observations, for which we turn to a high-resolution operational atmospheric analysis product. The operational analysis successfully captures the observed pattern of wind divergence (Fig. 1b). Interestingly, the wind convergence closely resembles the pattern of the Laplacian of Sea-Level Pressure $\left(\nabla^{2} \mathrm{SLP}\right.$ ) (Fig. 1c). This correspondence consistent with a Marine Atmospheric Boundary Layer (MABL) model ${ }^{16}$ (see Method Summary). Note that it is virtually impossible to see the correspondence between the wind convergence and SLP itself without taking the Laplacian. The Laplacian operator acts as a high-pass filter, unveiling the SST frontal effect that is masked by large-scale atmospheric circulations.

In contrast to the free atmosphere where wind velocities are nearly non-divergent, substantial divergence occurs in the MABL in the presence of strong friction and is proportional to the SLP Laplacian in the MABL model described in Methods Summary. Such a linear relation approximately holds in observations (Fig. 1f), with a correlation coefficient as high as 0.70 for a region where wind convergence and divergence are strong $\left(80^{\circ}-40^{\circ} \mathrm{W}, 30^{\circ}-48^{\circ} \mathrm{N}\right.$, dashed line box in Fig. 1c). Furthermore, consistent with the MABL model ${ }^{16}$ where SST variations force pressure adjustments, the pattern of Laplacian SST with sign reversed $\left(-\nabla^{2}\right.$ SST) exhibits some similarities to Laplacian SLP and wind convergences (Fig. 1d). These results indicate that MABL pressure adjustments to SST gradients near the Gulf Stream are important for surface wind divergence. Relatively high-pressures on the colder flank and relative low-pressures on warmer flank induce cross-frontal components of near-surface winds, leading to divergence and convergence (Fig. S1).

Previous studies suggested that warmer SSTs induce stronger vertical momentum mixing, and the enhanced mixing is responsible for meso-scale features in the surface wind convergence field ${ }^{9,10}$, consistent with a numerical model experiment focusing on near-surface adjustments ${ }^{17}$. Our observational result indicates the importance of the overlooked pressure adjustment mechanism, consistent with a recent short (a few days) regional model experiment for the Gulf Stream ${ }^{18}$ and also with a numerical study for tropical instability waves ${ }^{19}$. Note that the observed surface-wind convergence is roughly collocated with the axis of the Gulf Stream (Figs. 1e, S1).

Satellite observations further reveal that the Gulf Stream anchors a narrow rain band roughly collocated with the surface wind convergence (Fig. 2a). While there was evidence that the Gulf Stream affects precipitation ${ }^{20}$, our high-resolution analysis reveals that the narrow rain band meanders with the Gulf Stream front and is confined to its warmer flank with SSTs greater than $16^{\circ} \mathrm{C}$. This close co-variation in space is strongly indicative of an active role of the Gulf Stream. The precipitation pattern is well reproduced in the operational analysis (Fig. S2), with a bias of excessive rain rates compared to satellite observations.

The causality is further examined using the Atmospheric General Circulation Model (AGCM) ${ }^{4}$. It successfully captures the rain band following the meandering GulfStream although rain rate near the coast is somewhat too weak compared with satellite (Fig. 2b). When the SST is smoothed (see online method for detail), however, the 
narrow precipitation band disappears in the AGCM (Fig. 2c). Compared to the smoothed SST run, rain-bearing low-pressure systems tend to develop along the Gulf Stream front in the control simulation (Fig. S3). These results indicate that the narrow precipitation band in the western North Atlantic results from the forcing by the sharp SST front of the Gulf Stream.

Similar to precipitation, surface evaporation also exhibits a narrow banded structure on the offshore side of the SST front (Fig. S2). This evaporation band is consistent with a short-term field observation ${ }^{21}$. The amount of evaporation is slightly larger than precipitation, indicating that local evaporation supplies much of the water vapor for precipitation. The local enhancement of evaporation on the warmer flank of the Gulf Stream is due to enhanced wind speed and the large disequilibrium of air temperature from $\mathrm{SST}^{9,13}$.

Since precipitation off the U.S. east coast is often associated with deep weather systems, the above rainfall pattern suggests that the Gulf Stream's influence may penetrate to the free atmosphere. Indeed the upward motion across the Gulf Stream displays a deep structure extending to the upper troposphere (Fig. 3a). The upward motion is anchored by wind convergence in the MABL (Fig. 3a). The latter peaks at the sea surface and is strongly affected by SST (Fig. 1). It is interesting to note that although surface convergence and divergence are similar in magnitude (Fig. 1), the upward motion over surface wind convergence is much stronger and deeper than the downward motion over the wind divergence (Fig. 3a). This is suggestive of the importance of condensational heating above the MABL in developing the asymmetry between the upward and downward motion.

The upward wind velocity is strongest just above the MABL between 850 and 700 $\mathrm{hPa}$ (Fig. 3a). The horizontal distribution at these levels is quite similar to the distribution of the surface convergence. The Gulf Stream-trapped structure is clearly visible at $500 \mathrm{hPa}$ and remains discernible at $300 \mathrm{hPa}$ level (Fig. S4). Remarkably the divergence in the upper troposphere is also dominated by a meandering band following the Gulf Stream front (Fig. 3b), a pattern required by mass conservation with the tropopause acting virtually as a lid for the mean circulation.

Next we examine the occurrence of high clouds and infer cloud top temperature using three-hourly Outgoing Longwave Radiation (OLR) from satellite. Lower OLRs indicate lower temperatures and higher altitudes of cloud tops. Figure 3c shows the occurrence rate of OLR lower than $160 \mathrm{~W} \mathrm{~m}^{-2}$, which roughly corresponds to a cloudtop height of about $300 \mathrm{hPa}$. A narrow band of high occurrence hugs the SST front of the Gulf Stream in daytime. This high occurrence band is slightly shifted to the north compared with the bands of surface wind convergence and precipitation, consistent with the northward tilt of positive vertical velocity toward higher altitudes as shown in Fig. 3a. In nighttime, the Gulf Stream related signature is less prominent, suggesting a diurnal cycle of atmospheric convection. Our OLR result is consistent with fragmental evidence reported previously. Satellite observations show a high frequency of lightning occurrence along the Gulf Stream, indicative of cold ice clouds ${ }^{22}$. With a limited offshore coverage, coastal radars showed an echo height distribution suggestive of deep 
convection over the Gulf Stream ${ }^{23}$. The Gulf Stream's signature in high cloud as reported here is strong evidence that the influence of the Gulf Stream on the atmosphere is not limited to the MABL as reported previously ${ }^{9,10}$, but penetrates deeply into the upper troposphere.

In summary, the present study shows that the Gulf Stream affects the entire troposphere from the surface to the tropopause in a systematic manner (Fig. S1). In the MABL, the Gulf Stream directly influences air temperature and pressure fields. The resultant relatively low (high) pressures on the warm (cold) flank of the Gulf Stream front cause wind convergence (divergence). The Gulf Stream-induced convergence anchors the upward motion where precipitation is locally enhanced providing diabatic heating to the atmosphere. Remarkably, upper-tropospheric divergence shows a banded structure similar to the surface convergence and precipitation patterns, all meandering with the Gulf Stream. The deep influence of the Gulf Stream is further corroborated with frequent occurrence of high-level clouds along the Gulf Stream. We thus suggest that on the warmer flank of the Gulf Stream front roughly corresponding to the current axis, high instability of the atmosphere as manifested in enhanced latent and sensible heat flux leads to deep convection, enabling the influence of this warm ocean current to reach the entire troposphere.

Diabatic heating originating from surface heat fluxes over the North Atlantic Ocean is important for maintaining climatological circulations of the atmosphere both over the ocean basin and in downwind regions including Europe ${ }^{5,6}$. Deep latent heating by the Gulf Stream and the resultant upper-tropospheric divergence revealed from this study may be important for generating stationary Rossby waves that produce remote responses as illustrated in Fig. S5. Indeed, several recent studies suggested that SST anomalies near the Gulf Stream induce atmospheric circulation changes ${ }^{24-26}$, with significant feedback from changes in synoptic eddies ${ }^{27}$.

The Gulf Stream is the upper limb of Atlantic Meridional Overturning Circulation (AMOC), both displaying large variability in paleoclimate observations ${ }^{28}$. How effects of AMOC changes in the mid- to high latitudes are transmitted throughout the Northern Hemisphere has been a long-standing problem ${ }^{7}$. While recent coarse-resolution model simulations pointed to the tropical Atlantic as an important conduit ${ }^{29}$, our results suggest an additional, more direct pathway via the Gulf Stream's deep heating to the atmosphere. The AMOC is projected to slow down in response to the increasing greenhouse gas concentrations $^{8}$, giving rise to changes in the Gulf Stream ${ }^{30}$. It is conceivable that the Gulf Stream change will cause precipitation anomalies along the warm current and induce atmospheric circulation changes via adjustments in planetary wave and storm track.

\section{Methods Summary}

We used the following satellite products: QuikSCAT wind velocity on a $0.25^{\circ}$ grid from Remote Sensing Systems; the TRMM 3B43 precipitation product derived from the Tropical Rainfall Measuring Mission (TRMM) and other satellite data on a $0.25^{\circ}$ grid; three-hourly OLR data on a $1^{\circ}$ grid from NASA Langley Atmospheric 
Science Data Center; and monthly sea surface geostrophic current velocity on a $1 / 3^{\circ}$ Mercator grid distributed by Aviso. The monthly operational analysis was provided by the European Centre for Medium-Range Weather Forecasts with original model resolution of $38 \mathrm{~km}$ and re-gridded on a $0.5^{\circ}$ grid. The AGCM has T239 horizontal resolution ( $\sim 50 \mathrm{~km})$ and 48 levels $^{4}$. The analysis period is from January 2002 to February 2006 except for the OLR data that end in June 2005. More detailed information can be found in online methods.

To understand the relation between wind convergence and SLP Laplacian, we use a MABL mode ${ }^{16}$. Its momentum equations may be cast as $\varepsilon u-f v=-p_{x} / \rho_{0}$, $\varepsilon v+f u=-p_{y} / \rho_{0}$, where $x$ and $y$ are the eastward and northward coordinates, respectively, and $u$ and $v$ are the surface wind velocity in the respective directions, $\rho_{0}$ is the MABL density, $p$ is the pressure, $\varepsilon$ is the damping coefficient, and $f$ is the Coriolis parameter. It can be easily shown that the wind speed convergence is proportional to the Laplacian of pressure: $-\left(u_{x}+v_{y}\right) \rho_{0}=\left(p_{x x}+p_{y y}\right) \varepsilon /\left(\varepsilon^{2}+f^{2}\right)$. In the model, SLP is forced by $\mathrm{SST}^{16}: \varepsilon p+H\left(u_{x}+v_{y}\right)=-\gamma T$, where $T$ is the SST, $\gamma$ is a constant, and $H$ is the equivalent depth. Thus, a relation between the SST Laplacian and wind convergence is also expected, albeit weaker than that for the SLP Laplacian.

Full Methods and any associated references are available in the online version of the paper at www.nature.com/nature.

Received 1 August 2007; accepted 15 January 2008.

1. Sanders, F. Explosive cyclogenesis in the west-central North-Atlantic Ocean. 198184. Part I: Composite structure and mean-behavior. Mon. Wea. Rev. 114, 1781-1794 (1986).

2. Kuo, Y. H., Shapiro, M. A., Donall, E. G. The interaction between baroclinic and diabatic processes in a numerical-simulation of a rapidly intensifying extratropical marine cyclone. Mon. Wea. Rev. 119 368-384 (1991).

3. Young, G. S., \& Sikora, T. D. Mesoscale stratocumulus bands caused by Gulf Stream meanders. Mon. Wea. Rev. 131, 2177-2191 (2003).

4. Enomoto, T., Kuwano-Yoshida, A., Komori, N. \& Ohfuchi, W. Description of AFES 2: Improvements for high-resolution and coupled simulations. In High resolution numerical Modeling of the atmosphere and ocean. W. Ohfuchi and K. Hamilton (Eds.), chapter 5, 77-98, Springer, New York.

5. Hoskins B. J. \& Valdes, P. J. On the existence of storm-tracks. J. Atmos. Sci. 47, 1854-1864 (1990).

6. Held, I. M., Ting, M., \& Wang, H. Northern winter stationary waves: Theory and modeling. J. Climate 15, 2125-2144 (2002).

7. Broecker, W. S. Does the trigger for abrupt climate change reside in the ocean or in the atmosphere? Science 300, 1519-1522 (2003).

8. Meehl, G. A. et al. Global climate projections. In Climate Change 2007: The Physical Scientific Basis. Solomon S. et al. Eds., (Cambridge University Press, Cambridge, 2007). 
9. Xie, S.-P. Satellite observations of cool ocean-atmosphere interaction. Bull. Am. Met. Soc. 85, 195-208 (2004).

10. Chelton D. B., Schlax, M. G., Freilich, M. H. \& Milliff, R. F. Satellite measurements reveal persistent small-scale features in ocean winds. Science 303, 978983 (2004).

11. Xie S.-P., Hafner, J., Tanimoto, Y., Liu, W. T., Tokinaga, H. \& Xu, H. Bathymetric effect on the winter sea surface temperature and climate of the Yellow and East China Seas. Geophys. Res. Lett. 29, 2228, doi:10.1029/2002GL015884 (2002).

12. Chelton, D. B. \& Wentz, F. J. Global microwave satellite observations of sea surface temperature for numerical weather prediction and climate research. Bull. Am. Met. Soc. 86, 1097-1115 (2005).

13. Tokinaga, H., Tanimoto, Y. \& Xie, S.-P. SST-induced surface wind variations over the Brazil-Malvinas confluence: Satellite and in situ observations. J. Climate 18, 34703482 (2005).

14. O’Neill, L. W., Chelton, D. B., Esbensen, S. K. \& Wentz, F. J. High-resolution satellite measurements of the atmospheric boundary layer response to SST variations along the Agulhas Return Current. J. Climate 18, 2706-2723 (2005).

15. Liu, W. T. Progress in scatterometer applications. J. Oceanogr. 58, 121-136 (2002).

16. Lindzen, R. S., \& Nigam, R. S. On the role of sea surface temperature gradients in forcing low level winds and convergence in the tropics. J. Atmos. Sci. 44, 2418-2436 (1987).

17. Skyllingstad, E. D., Vickers, D., Mahrt, L., Samelson R. Effects of mesoscale seasurface temperature fronts on the marine atmospheric boundary layer. Boundary-Layer Meteorol., 123, 219-237 (2007).

18. Song, Q., Cornillon, P. \& Hara, T. Surface wind response to oceanic fronts. J. Geophys. Res. 111, C12006, doi:10.1029/2006JC003680 (2006).

19. Small, R. J., Xie, S.-P. \& Wang, Y. Q. Numerical simulation of atmospheric response to Pacific tropical instability waves. J. Climate, 16, 3723-3741 (2003).

20. Pan, J., Yan, X.-H., Zheng, Q. \& Liu, W. T. Observation of western boundary current atmospheric convergence zones using scatterometer winds. Geophys. Res. Lett. 29, 1832, doi:10.1029/2002GL015015 (2002).

21. Neiman, P. J. \& Shapiro, M. A. The life-cycle of an extratropical marine cyclone. Part-I: Frontal-cyclone evolution and thermodynamic air-sea interaction. Mon. Wea. Rev. 121, 2153-2176 (1993).

22. Christian, H. J., et al. Global frequency and distribution of lightning as observed from space by the Optical Transient Detector. J. Geophys. Res. 108 (D1), 4005, doi:10.1029/2002JD002347 (2003).

23. Trunk, T. J. \& Bosart, L. F. Mean radar echo characteristics during project GALE. Mon. Wea. Rev. 118, 459-469 (1990).

24. Czaja, A. \& Frankignoul, C. Observed impact of Atlantic SST anomalies on the North Atlantic Oscillation. J. Climate 15, 606-623 (2002). 
25. Ciasto, L. M., \& Thompson, D. W. J. North Atlantic atmosphere-ocean interaction on intraseasonal time scales. J. Climate 17, 1617-1621 (2004).

26. Watanabe, M., Jin, F. F., \& Pan, L. Accelerated iterative method for solving steady problems of linearized atmospheric models. J. Atmos. Sci. 63, 3366-3382 (2006).

27. Peng, S., \& Robinson, W.A. Relationships between atmospheric internal variability and the responses to an extratropical SST anomaly. J. Clim. 14, 2943-2959 (2001)

28. Lund, D.C., Lynch-Stieglitz, J. \& Curry W.B. Gulf Stream density structure and transport during the last millennium. Nature 444, 601-604 (2006).

29. Timmermann, A. et al. The influence of a weakening of the Atlantic meridional overturning circulation on ENSO. J. Climate 20, 4899-4919 (2007).

30. Dai, A., Hu, A., Meehl, G. A., Washington, W. M., \& Strand, W. G. Atlantic thermohaline circulation in a coupled general circulation model: Unforced variations versus forced changes. J. Climate 18, 3270-3293 (2005).

Supplementary Information accompanies the paper on www.nature.com/nature.

Acknowledgements We thank M. Watanabe and K. Yamazaki for invaluable discussion. SM, NK, and AKY are supported by grant-in-aid for scientific research (kaken-hi) and SM by the 21st century center of excellence program on "Neo-Science of Natural History" led by H. Okada, both from the Ministry of Education, Culture, Sports, Science and Technology, Japan; SPX by NASA, NOAA, NSF and JAMSTEC. The numerical calculation was carried out on the Earth Simulator under support of JAMSTEC. IPRC/SOEST publication \#xxx/yyy.

Author contributions S. M. analyzed satellite and operational data, N. K. and A. K.-Y. conducted and analyzed AGCM experiments, R. J. S. conducted experiments using linear baroclinic model and its analysis, S. M. and S.-P. X. wrote the paper. All authors discussed the results and commented on the manuscript.

Author Information Reprints and permissions information is available at npg.nature.com/reprintsandpermissions. The authors declare no competing financial interests. Correspondence and requests for materials should be addressed to S. M. (minobe@sci.hokudai.ac.jp). 
Figures
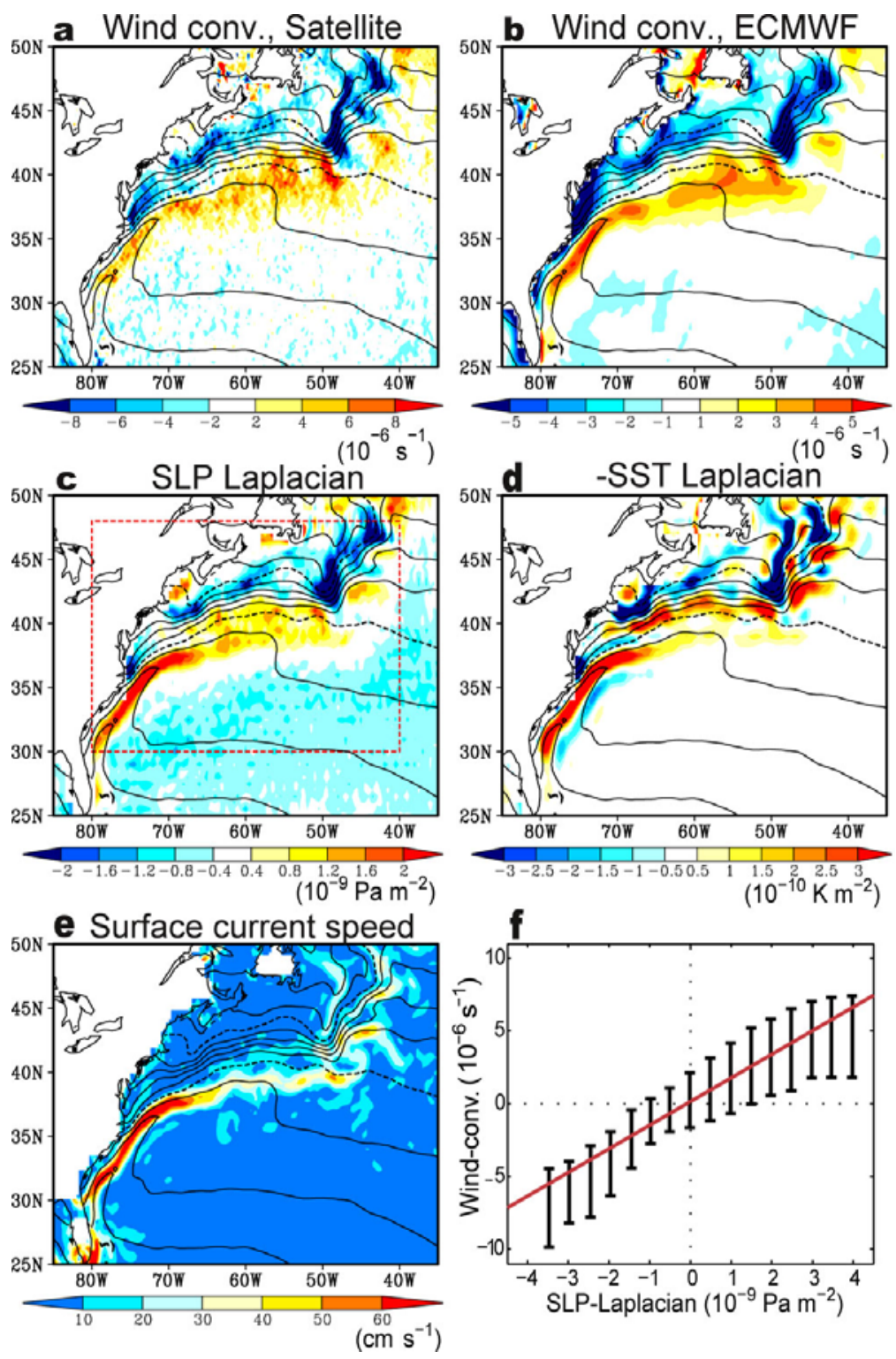

Figure 1. Annual climatology of surface parameters. $10-\mathrm{m}$ wind convergence (color) in (a) QuikSCAT satellite observations and (b) the ECMWF analysis. (c) SLP Laplacian in the ECMWF analysis, (d) sign-reversed SST Laplacian, and (e) surface geostrophic current speed, along with SST contours $\left(2^{\circ} \mathrm{C}\right.$ interval and dashed contours for $10^{\circ} \mathrm{C}$ and $\left.20^{\circ} \mathrm{C}\right)$. (f) Relationship between the SLP-Laplacian and wind convergence based on monthly climatology in the red-dashed box in panel (c), with \pm 1 standard deviation of wind convergence for each bin of SLP (error bar) and the regression line. 

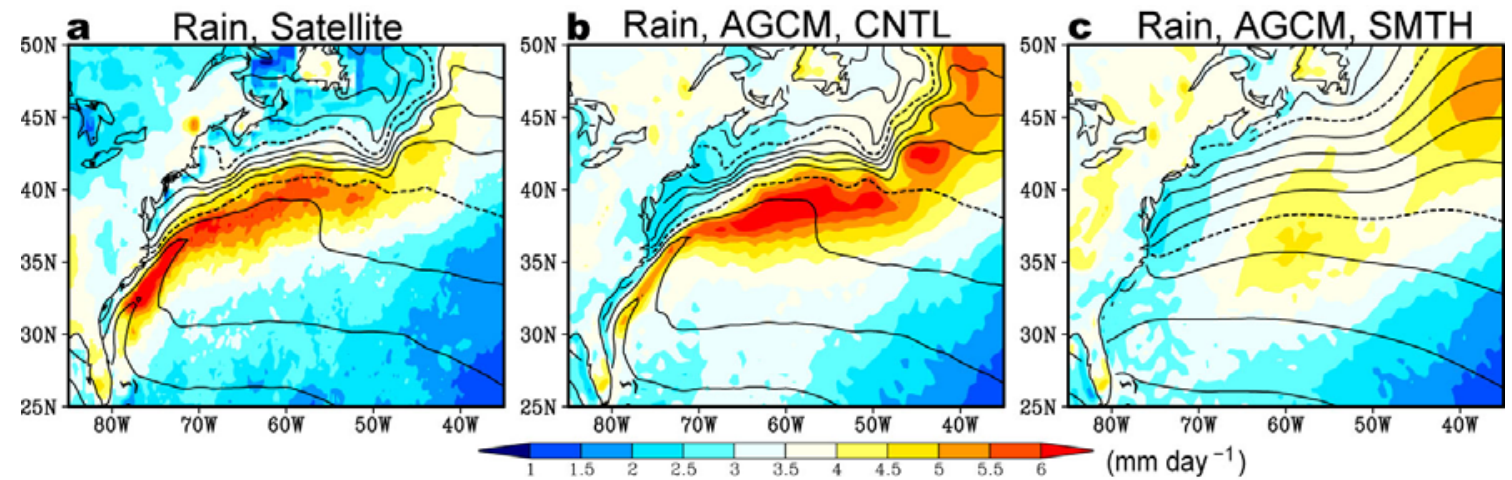

Figure 2. Annual climatology of rain rate: (a) observed by satellites, and in the AGCM with (b) observed and (c) smoothed SSTs. Contours are for SST as in Fig. 1.
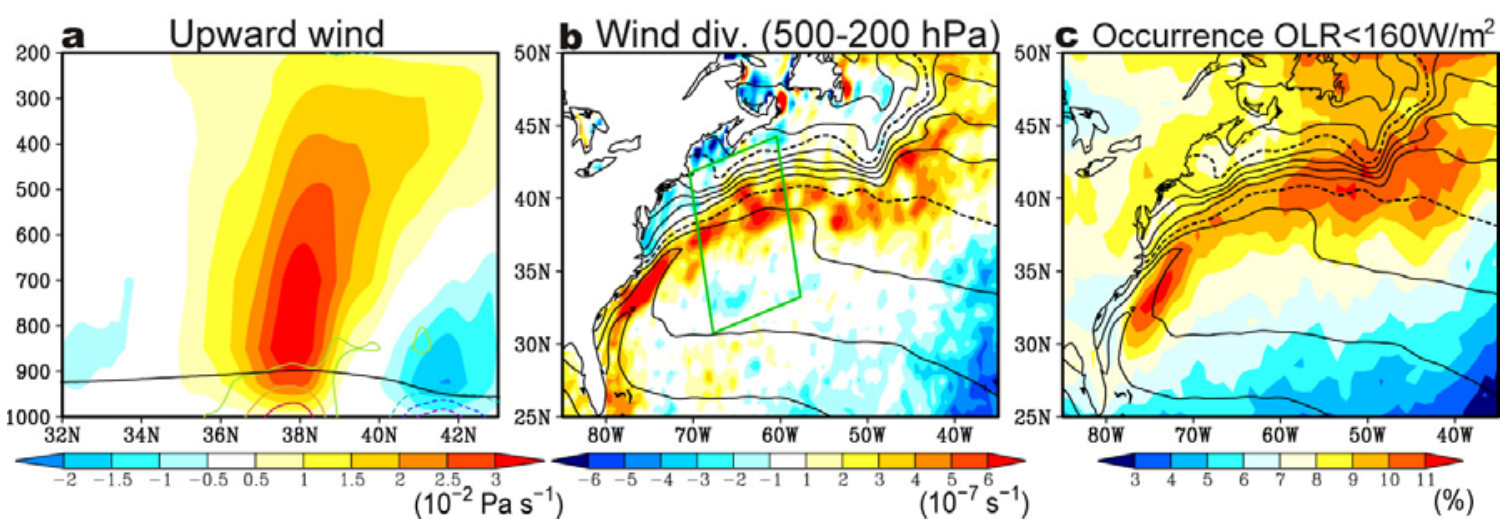

Figure 3. Annual climatology of parameters connecting MABL and free atmosphere: (a) vertical wind velocity (upward positive; color), boundary layer height (black curve), and wind convergence (contours for $\pm 1,2,3 \times 10^{-6} \mathrm{~s}^{-1}$ ) averaged in the along-front direction in the green box in panel (b), based on the ECMWF analysis; (b) upper-tropospheric wind divergence averaged between 200 and $500 \mathrm{hPa}$; (c) occurrence frequency of daytime satellite-derived OLR smaller than $160 \mathrm{~W} \mathrm{~m}^{-2}$ (color). Contours in panels (b) and (c) are for SST as in Fig. 1. 


\section{Online Methods}

ECMWF Operational Analysis. Wind velocity at $10 \mathrm{~m}$ height, sea-level pressure (SLP), precipitation amount, surface latent heat flux (evaporation), and vertical wind velocity are used from the ECMWF operational product. Among these parameters, wind velocity and SLP are taken from the analysis while precipitation and latent heat flux are taken from the forecast output. Consistency between the analysis and the forecast was confirmed by a comparison of SLPs between the analysis and forecast. The atmospheric model uses a spectral dynamical core with TL511 resolution, equivalent to a grid resolution of approximately $38 \mathrm{~km}$. Combined with this high model resolution, the use of high-resolution Real-Time, Global (RTG) SST $^{31}$ substantially improves the representation of the near-surface atmospheric response to SST variations ${ }^{12}$.

Atmospheric GCM. We conduct numerical experiments using an AGCM, called the Atmospheric general circulation model For the Earth Simulator (AFES) version $2^{4}$. The horizontal resolution is T239, with 48 vertical levels. AFES employs daily RTG-SST as the lower boundary condition in the control simulation. We also conduct an AGCM experiment by spatially smoothing SSTs over the central-western North Atlantic $\left(100^{\circ}\right.$ $\left.30^{\circ} \mathrm{W}, 25^{\circ}-55^{\circ} \mathrm{N}\right)$. The smoothing is conducted by applying a 1-2-1 running mean filter both in the zonal and meridional directions 100 times on a $0.5^{\circ}$ grid. This low-pass filter has the half power point at $26.8^{\circ}$.

Satellite Data. Four satellite products are analyzed. Near surface wind velocity is measured by seawinds scatterometer sensor (referred to as QuikSCAT) on QuikBird satellite. The seawinds sensor is an active radar scatterometer using high-frequency microwave pulses. We use twice daily QuikSCAT product from the Remote Sensing Systems (http://www.remss.com).

For precipitation, we use the Tropical Rainfall Measuring Mission (TRMM) 3B43 product, derived from TRMM and other satellite observations: geosynchronous infrared radiometer, Special Sensor Microwave/Imager (SSM/I), rain gauge, and the TRMM 3B31 product based on the precipitation radar and microwave imager on the TRMM satellite. The TRMM 3B43 product is available at Goddard Earth Sciences Data and Information Services Center (http://daac.gsfc.nasa.gov). Similar results are obtained from another satellite-based precipitation estimate derived from a series of SSM/I satellites.

Global three-hourly OLR data is provided as a part of Surface Radiation Budget dataset available at Langley Atmospheric Science Data Center of NASA (http://eosweb.larc.nasa.gov). We analyze the data from January 2002 to June 2005 (the latest). We identify daytime as when Universal Time is from 12:00 to 21:00, which corresponds to local time from 7:00 to $16: 00$ at $75^{\circ} \mathrm{W}$.

Sea surface geostrophic currents are estimated from satellite altimetry data and the mean dynamic topography. The data are obtained from AVISO (http://www.aviso.oceanobs.com/). The satellite altimetry data combine measurements from the Topex/Poseidon, ERS-1/2, Jason-1 and Envisat satellites ${ }^{32}$ while the mean dynamic topography is estimated from geoid model, hydrograph data, and buoys ${ }^{33}$. 
31. Thiébaux, J., E. Rogers, W. Wang, \& Katz, B. A new high-resolution blended realtime global sea surface temperature analysis. Bull. Amer. Meteor. Soc., 84, 645-656 (2003).

32. Ducet, N., \& Le Traon, P.-Y. A comparison of surface eddy kinetic energy and Reynolds stresses in the Gulf Stream and the Kuroshio Current systems from merged TOPEX/Poseidon and ERS-1/2 altimetric data. J. Geophys. Res., 106 (C8), 16,60316,622 (2001).

33. Rio, M.-H., \& Hernandez, F. A mean dynamic topography computed over the world ocean from altimetry, in situ measurements, and a geoid model. J. Geophys. Res., 109, C12032, doi:10.1029/2003JC002226 (2004). 


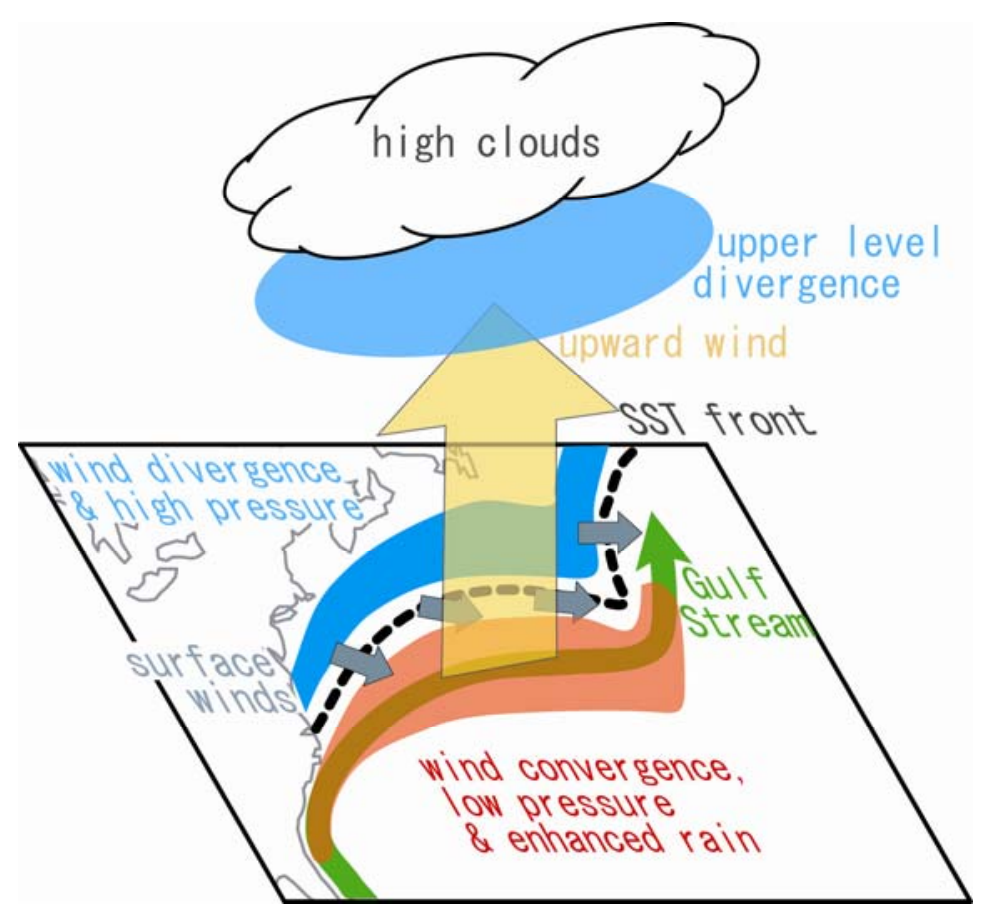

Figure S1. Summary of the climatic responses to the Gulf Stream. On the offshore flank of the SST front (black dashed curve) of the Gulf Stream (green long arrow), surface wind convergence associated with low pressure (positive SLP Laplacian), and enhanced rain occur (red shade). On the onshore flank of the front, surface wind divergence associated with high pressure (negative SLP Laplacian) occurs (blue shade). The distribution of the wind convergence and divergence is closely associated with surface winds across the SST front (short gray arrows). Anchored by the wind convergence and enhanced precipitation, upward motion penetrates into the upper troposphere (yellow arrow). The upward wind velocity is associated with the upperlevel horizontal divergence (blue oval) and frequent occurrence of high-level clouds. 

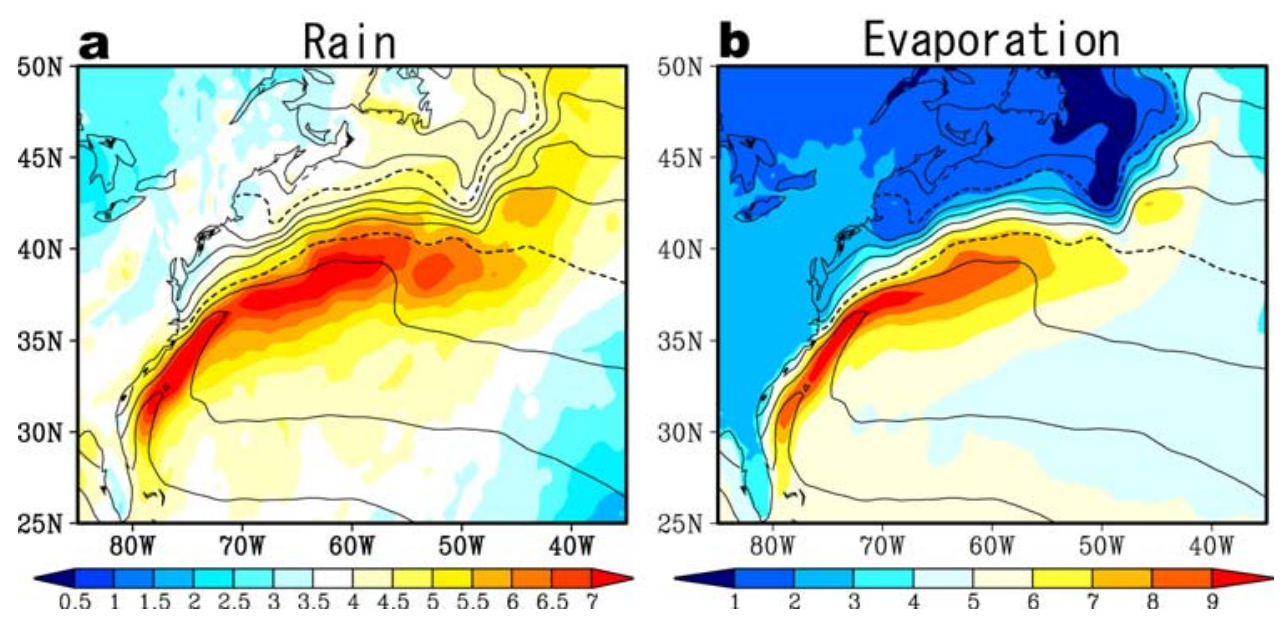

Figure S2. Annual mean climatology of (a) rain and (b) evaporation rate in the ECMWF operational analysis (color) along with annual mean SST (contour). The units of color bar are mm day ${ }^{-1}$, and contour interval is $2^{\circ} \mathrm{C}$ with dashed contours for $10^{\circ} \mathrm{C}$ and $20^{\circ} \mathrm{C}$. 

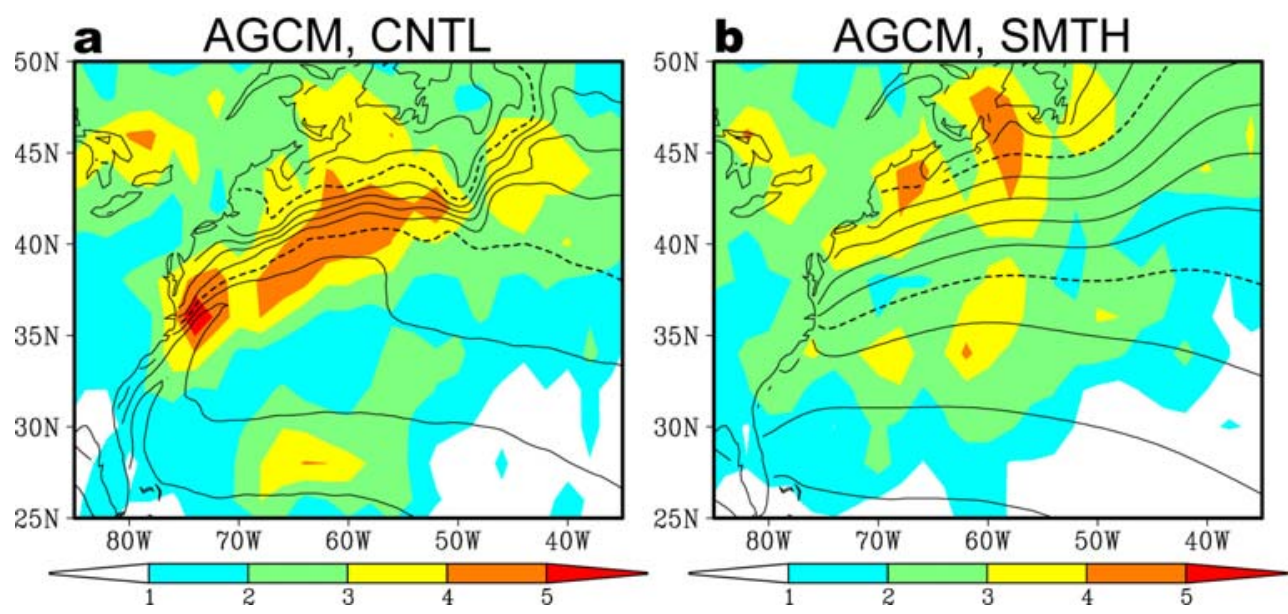

Figure S3. Annual mean climatology of cyclone number density (color) simulated by the AGCM using observed (a) and smoothed (b) SSTs (contours). A cyclone is detected as the sea-level pressure minimum within a circular range of $300 \mathrm{~km}$ radius on 6 -hourly maps. The units of the color bar are number per year in a bin of $2.0^{\circ} \times 2.0^{\circ}$, and contour interval is $2^{\circ} \mathrm{C}$ with the $10^{\circ} \mathrm{C}$ and $20^{\circ} \mathrm{C}$ contours dashed. 

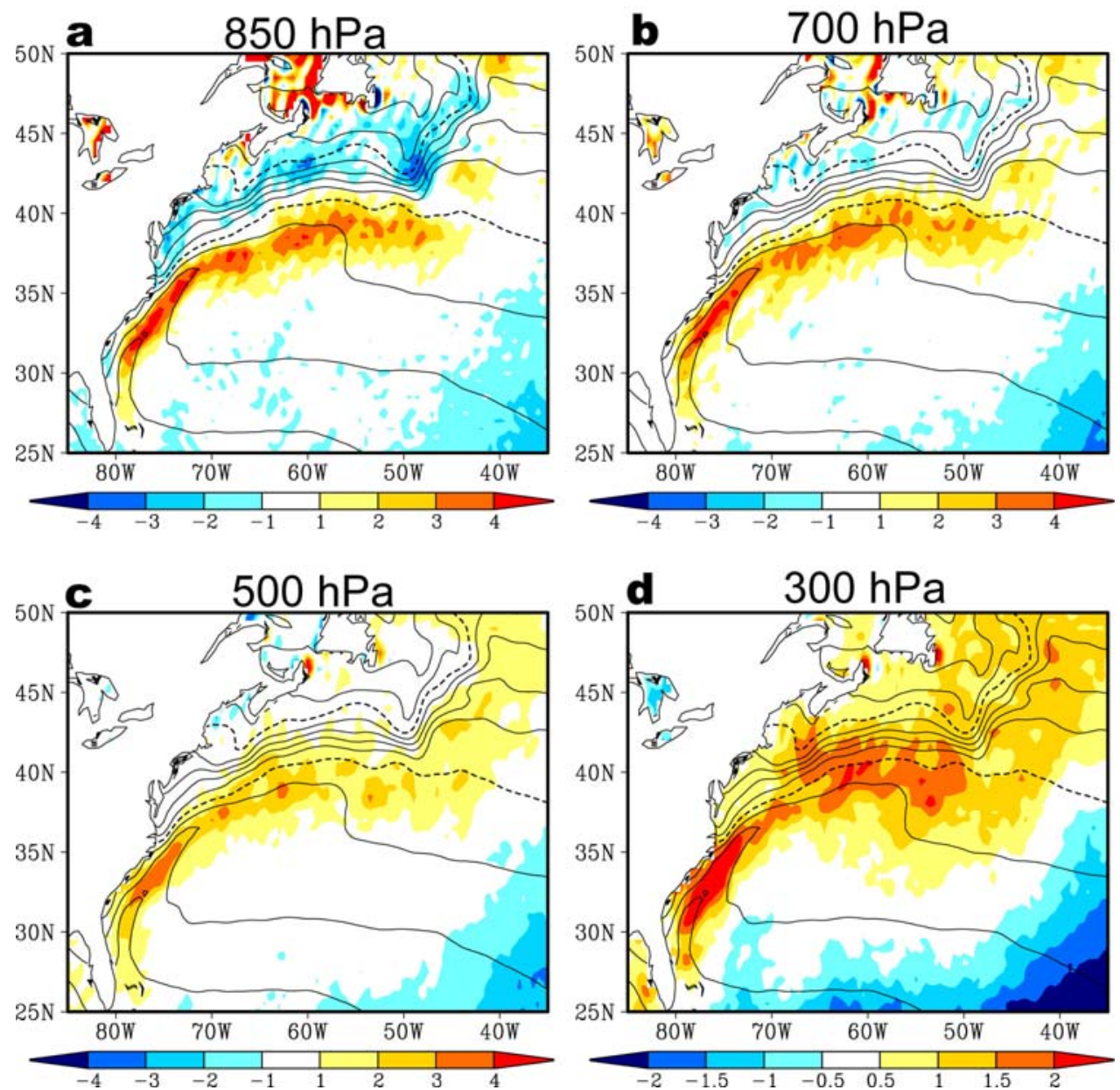

Figure S4. Annual mean climatology of upward vertical winds (color) at (a) 850, (b) 700, (c) 500 and (d) $300 \mathrm{hPa}$ along with annual mean SST (contour). The unit of color bar is $0.01 \mathrm{~Pa} \mathrm{~s}^{-1}$, and contour interval is $2^{\circ} \mathrm{C}$ with dashed contours for $10^{\circ} \mathrm{C}$ and $20^{\circ} \mathrm{C}$. Note that color scale for panel $\mathrm{d}$ is different from the others. 

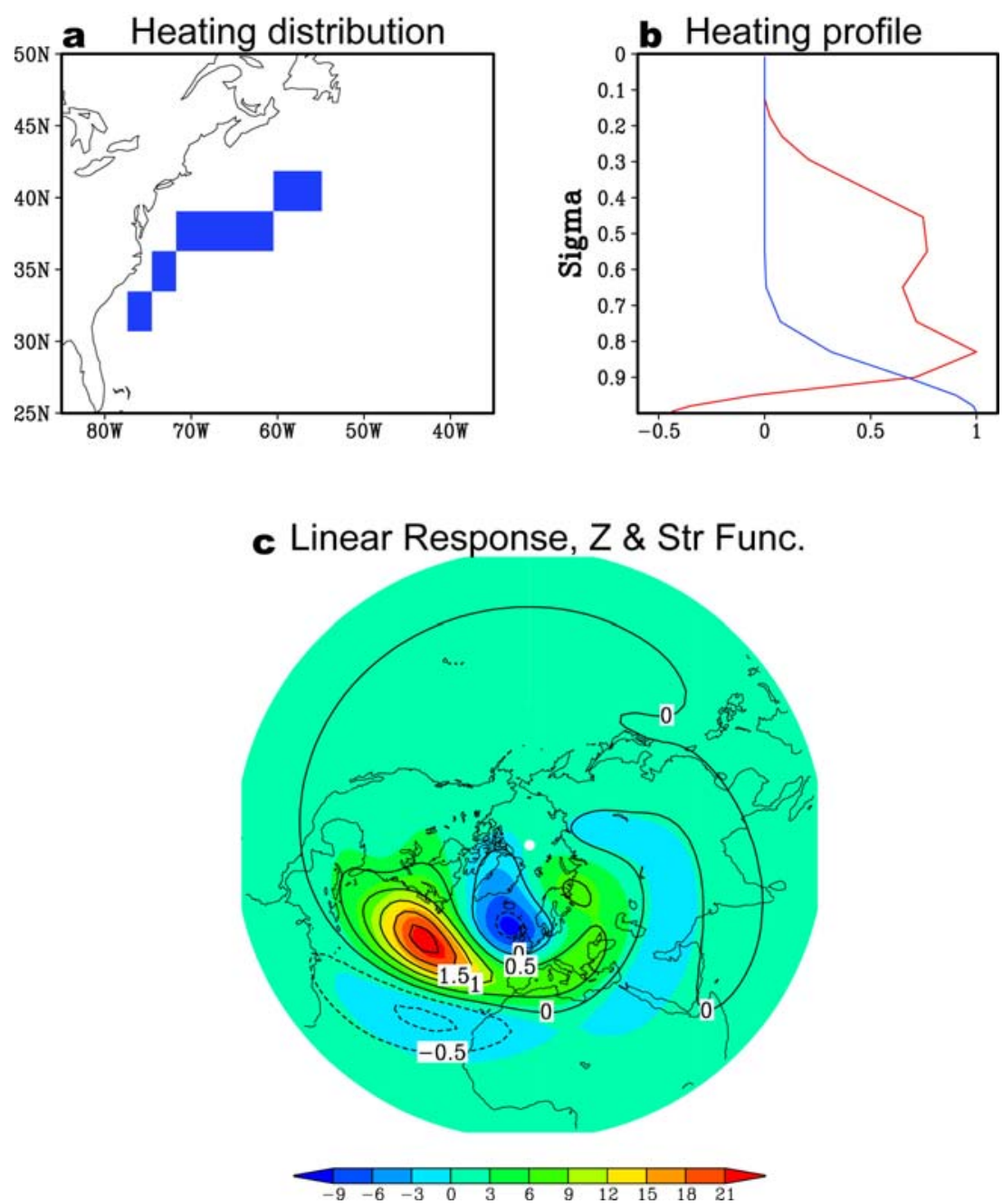

Figure S5. Diabatic heating by the Gulf Stream: horizontal distribution (a) and vertical profile (b) (red for latent and blue for sensible heating). (c) Atmospheric response at 250 hPa in the Linear Baroclinic Model (LBM): geopotential height (color in m) and stream function (contour in $10^{6} \mathrm{~m}^{2} \mathrm{~s}^{-1}$ ). The spatial distribution of the heating in (a) is centered along the Gulf Stream and its extension, based on the present study. The vertical heating profile in (b) is determined from Japanese 25 -year Re-Analysis (JRA25) ${ }^{1}$ for a region $65^{\circ}-50^{\circ} \mathrm{W}, 35^{\circ}-39^{\circ} \mathrm{N}$. Note that the latent heating has a deep vertical structure, consistent with our results. The heating was scaled so that the vertically integrated sensible heating is $70 \mathrm{~W} \mathrm{~m}^{-2}$, and the latent heat release is $180 \mathrm{~W} \mathrm{~m}^{-2}$, based on annual mean surface fluxes along the Gulf Stream in NCEP/NCAR reanalysis ${ }^{2}$, though JRA25 exhibits somewhat larger values. The $\mathrm{LBM}^{3}$ is linearized about a zonal and annual mean basic state derived from the NCEP/NCAR reanalysis, at T42 resolution with 20 sigma levels in the vertical. Similar linear models are able to simulate the salient features of the observed stationary waves when forced by realistic diabatic heating and eddy fluxes ${ }^{4,5}$. The atmospheric response to the Gulf Stream heating features positive height anomalies over the mid-latitude North Atlantic and negative anomalies to the north and south, contributing significantly to the westerly jet from North America to Europe. The maximum geopotential height anomaly exceeds $20 \mathrm{~m}$ in LBM, a significant fraction of the standard deviation (42 m) of zonal variations of the annual climatology in $35^{\circ}-40^{\circ} \mathrm{N}$. 


\section{References}

1. Onogi, K. et al. The JRA-25 Reanalysis. J. Met. Soc. Japan 85, 369-432 (2007)

2. Kalnay, E., et al. The NCEP/NCAR 40 year re-analysis project. Bull. Amer. Meteor. Soc. 77, 437-471 (1996).

3. Watanabe, M. \& Kimoto, M. Atmosphere-ocean coupling in the North Atlantic: a positive feedback. Quart. J. Roy. Met. Soc. 126, 3343-3369 (2000).

4. Hoskins B. J. \& Valdes, P. J. On the existence of storm-tracks. J. Atmos. Sci. 47, 1854-1864 (1990).

5. Held, I. M., Ting, M., \& Wang, H. Northern winter stationary waves: Theory and modeling. J. Climate 15, 2125-2144 (2002). 
13 March 2008 | www.natureasiapacific .com
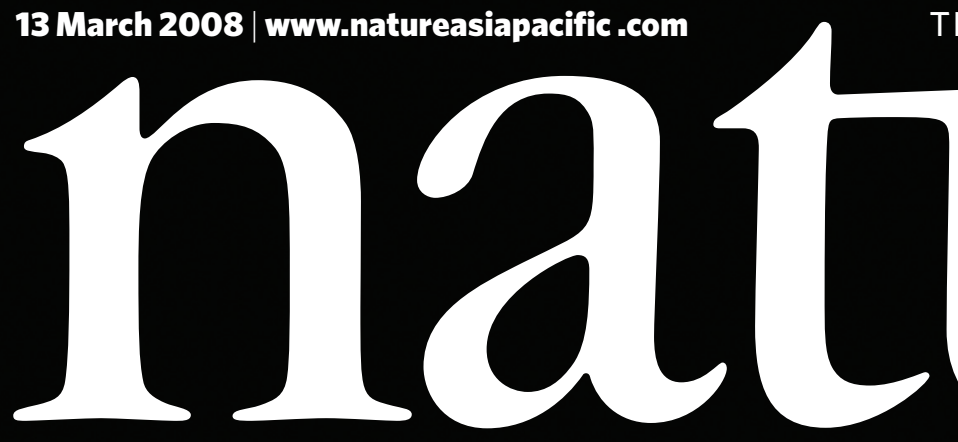

THE INTERNATIONAL WEEKLY JOURNAL OF SCIENCE

GIANT TELESCOPES Theracetoa 30-metremirror

RADICAL BIOCHEMISTRY C. difficile's surprising entyme SUPRAMOLECULAR SELF-ASSEMBIY DNA bricks make complexitysimple
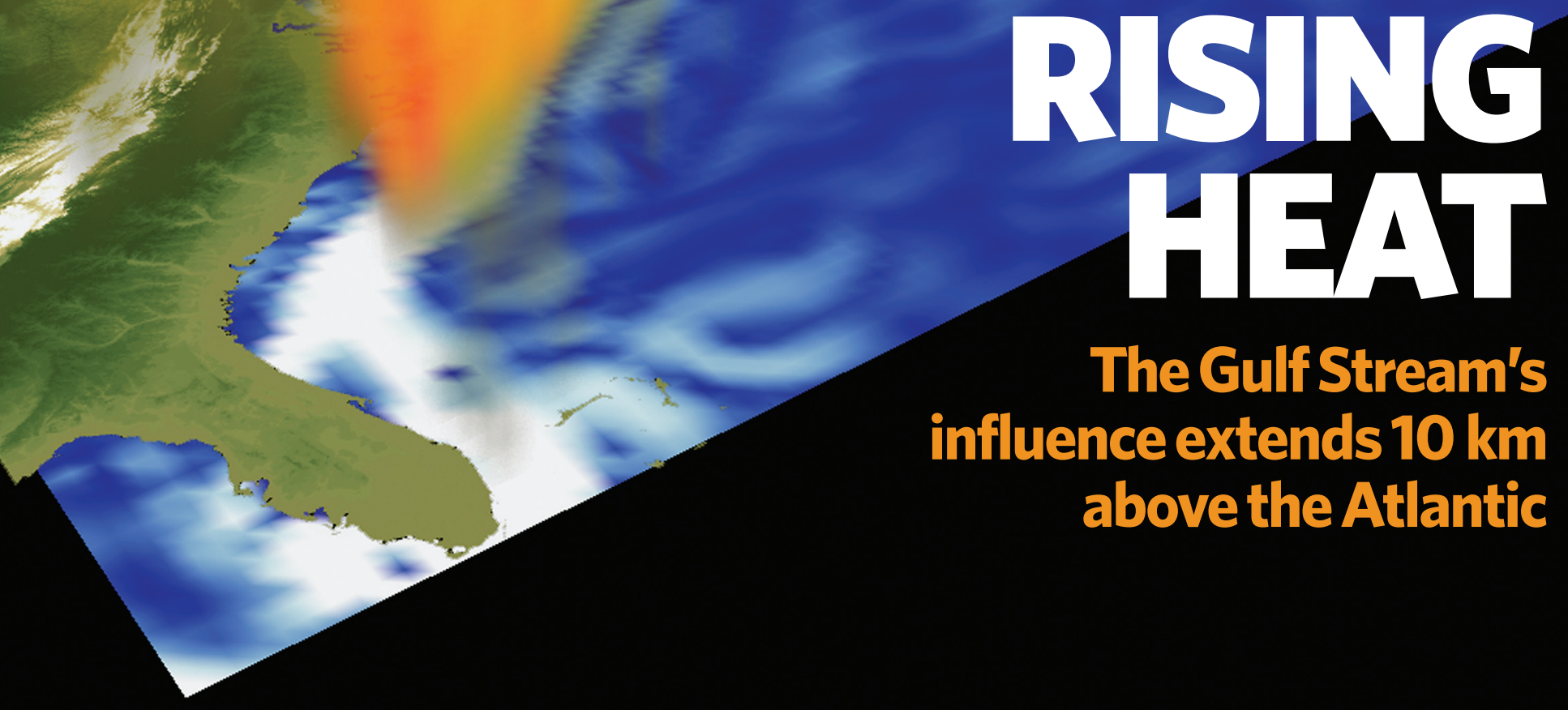

The Gulf Stream's above the Atlantic

NATUREJOBS Florida targets biotech

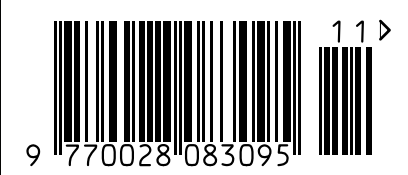

